\title{
A case of subdural hematoma with a medical history of hemophilia a and a review of related literature
}

\author{
Yi Zhao, Xin-Jie Bao*, Yong Yao, Yuan-Fan Yang, Jun-Ji Wei, Wen-Bin Ma and Ren-Zhi Wang
}

*Correspondence:
xinjieabao@163.com
Department of Neurosurgery,
Peking Union Medical College
Hospital, Chinese Academy of
Medical Sciences, 1 Shuaifuyuan,
Wangfujing, Beijing 100730, China

* Correspondence:

xinjieabao@163.com

Peking Union Medical College

Hospital, Chinese Academy of

Wangfujing, Beijing 100730, China

\begin{abstract}
Background: Intracranial hemorrhage is the most common emergency in the neurology department, and patients with a medical history of hemophilia have a risk of severe bleeding.

Case presentation: A 56-year-old man was admitted to the emergency department in our hospital. He was diagnosed with hemophilia A and subdural hematoma. We administered an infusion of factor VIII to decrease the risk of bleeding and improve the prognosis. Factor VIII infusion is the most important factor in treating hemophilia A patients.

Conclusion: We recommend carefully checking coagulation function and the medical history once these patients are admitted, especially in the emergency department.

Keywords: Intracerebral hemorrhage, Hemophilia, Factor VIII
\end{abstract}

\section{Background}

Intracranial hemorrhage $(\mathrm{ICH})$ is a common emergency in neurology departments and includes many complications. Hemophilia is a rare complication that increases the risk of bleeding in conditions such as subdural hematoma (SDH), ICH, and subarachnoid hemorrhage (SAH). Acute SDH is a lethal disease with a high mortality rate, and the mortality of patients with hemophilia is also high [1]. Thus, improved monitoring and early treatment for SDH are more necessary than previously thought. Here, we report a case of SDH in a male patient with a medical history of hemophilia. We administered an infusion of factor VIII and provided adjunctive treatment during the perioperative period, successfully saving his life. In addition, we summarize the characteristics of treatment for SDH patients with a history of hemophilia A through a literature review.

\section{Case presentation}

A 56-year-old man went into a coma after presenting with a headache and vomiting spontaneously $8 \mathrm{~h}$ before he was admitted to the hospital. The patient's medical history was normal, except for hemophilia A. Due to a lack of factor VIII in the admitting hospital, he was transferred to our hospital.

(c) The Author(s). 2018 Open Access This article is distributed under the terms of the Creative Commons Attribution 4.0 International License (http://creativecommons.org/licenses/by/4.0/), which permits unrestricted use, distribution, and reproduction in any medium, provided you give appropriate credit to the original author(s) and the source, provide a link to the Creative Commons license, and indicate if changes were made. The Creative Commons Public Domain Dedication waiver (http://creativecommons.org/ publicdomain/zero/1.0/) applies to the data made available in this article, unless otherwise stated. 
On arrival, the patient's Glasgow Coma Score was 6/15. The diameters of the left and right pupil were $4 \mathrm{~mm}$ and $6 \mathrm{~mm}$, respectively. The light reflex was absent in the right eye and diminished in the left. The patient had hypermyotonia with an absence of myodynamia, and the Babinski sign was positive on both sides. Coagulation function was assessed. The activated partial thromboplastin time (APTT) was increased to $103.4 \mathrm{~s}$, factor VIII inhibitor was 0 , and fibrinogen was decreased to $1.64 \mathrm{~g} / \mathrm{L}$. A computed tomography (CT) scan showed right acute parietal and frontotemporal SDH with a 15-mm midline shift. The hematoma volume was approximately $60 \mathrm{ml}$.

The patient received a $250-\mathrm{ml}$ infusion of mannitol as soon as he was admitted. We held consultations in the Hematology Department, intensive care unit, and Anesthesiology Department. We agreed that infusing sufficient factor VIII was the most important factor in the perioperative period. The operation proceeded normally, and the amount of bleeding was $4 \mathrm{U}$. Preoperative and postoperative CT scans are shown in Fig. 1. Based on the consultations, we infused the patient with $2400 \mathrm{U}(40 \mathrm{U} / \mathrm{kg})$ of factor VIII during the operation. We continued to infuse $2400 \mathrm{U}$ of factor VIII per $12 \mathrm{~h}$ for the first 3 days after surgery, $1600 \mathrm{U}$ per $12 \mathrm{~h}$ from the 4th day to the 1st week, and $1000 \mathrm{U}$ per day from the 1 st week to the 2 nd week. The APTT was 34-57 s 2 weeks after the operation. When he was released from the hospital, factor VIII inhibitor was 0 , and factor VIII activity was $25.9 \%$. The APTT was $55.5 \mathrm{~s}$, and the international normalized ratio was 1.16 . The right oculomotor nerve showed paralysis with ptosis, and the diameter of the pupil was $5 \mathrm{~mm}$. The right eye could abduct only. Myodynamia had recovered, and the Babinski sign was negative on both sides. He had a follow-up visit 3 months after discharge, and right oculomotor and right eye movements were observed. Cranioplasty was required after 6-12 months.

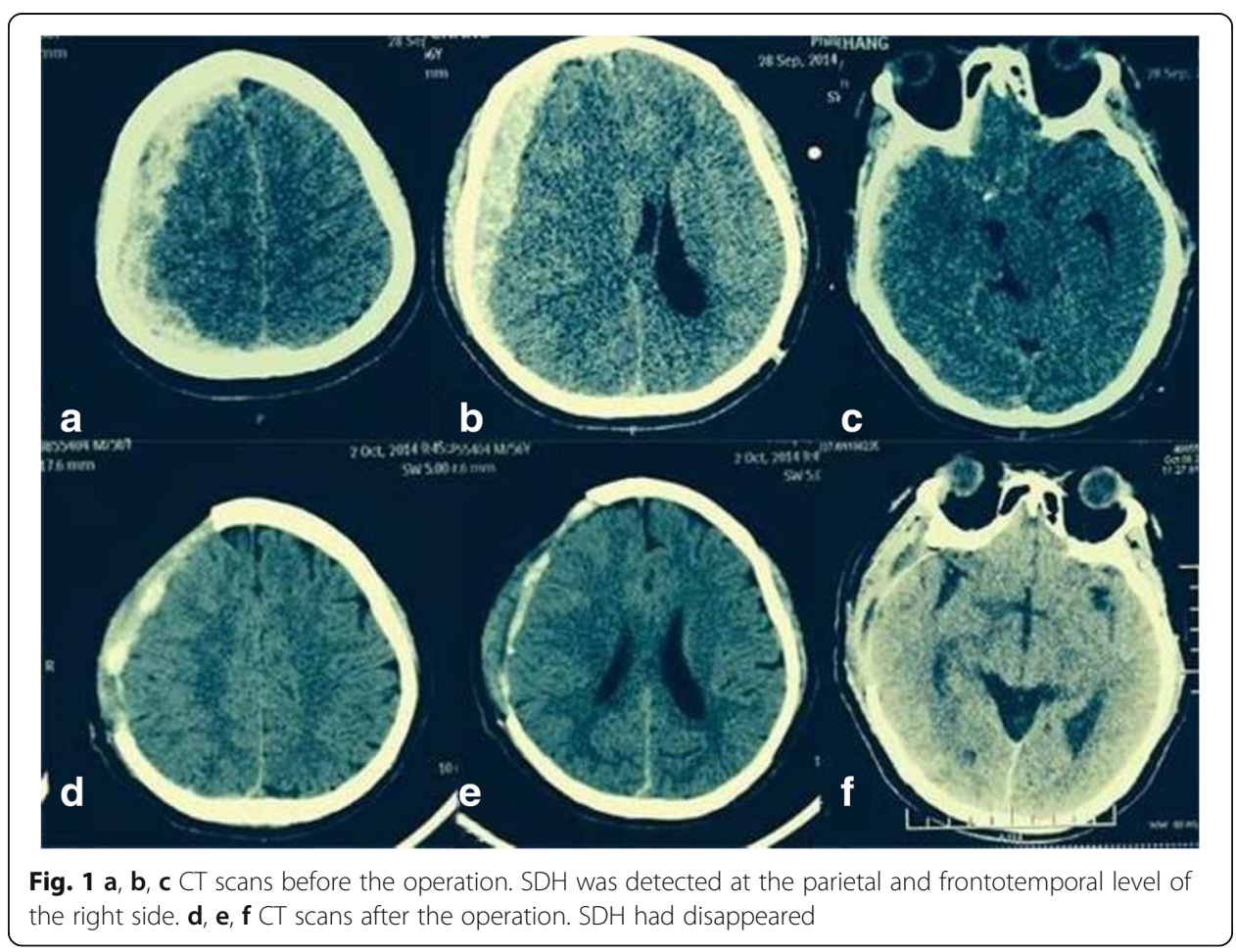




\section{Discussion}

Hemophilia is an inherited bleeding disorder that can be classified into three types based on deficiency of the following coagulation factors: factor VIII (hemophilia A), factor IX (hemophilia B), and factor XI (hemophilia C). Hemophilia is classified as severe (factor level $<0.01 \mathrm{IU} / \mathrm{ml}$ ), moderate (factor level $<0.05 \mathrm{IU} / \mathrm{ml}$ ), and mild (factor level $\geq 0.05$ and $<0.4$ ). Hemophilia A, which occurs in approximately 1 in 5000 live male births, is more common and more likely to be severe, and morbidity is higher among males than among females. A prolonged APTT is a factor used to identify hemophilia. Primary treatment for hemophilia A is infusion of sufficient factor VIII and an emergency operation. Monitoring coagulation function is also important during the perioperative period.

Our patient was a middle-aged male who had inherited hemophilia A. He was admitted to the emergency room following a diagnosis of SDH. Because of his clinical history of hemophilia A and the severity of the disease, we measured his factor VIII activity levels in an APTT-based assay (APTT prolongation time). Normally, a prolonged APTT increases as hemophilia severity worsens. However, APTT might be normal in mild factor deficiencies. Patients with severe hemophilia rarely exhibit mild clinical signs [2] but can present with normal von Willebrand factor antigen levels, platelet counts, and prothrombin times.

Once the patient was admitted, normal treatment to reduce intracranial pressure was administered. A CT scan was performed upon his arrival to the hospital to evaluate his illness [3]. The diagnoses of SDH and hemophilia A were confirmed. Mild hemophilia is observed with bleeding in response to injury or surgery, such as bleeding of the teeth or mucous bleeding, mainly later in life. ICH and joint destruction are the two most important late complications observed patients with hemophilia. $\mathrm{ICH}$, one of the most serious and life-threatening events, is relatively rare in patients with hemophilia. ICH can occur spontaneously or after trauma; it may also be caused by other risk factors (e.g., severe diseases and infection). Frequently, the pathogenesis of ICH is unknown $[4,5]$.

Because of its etiology, hemophilia A requires treatment with factor VIII. Prophylaxis is effective in decreasing the incidence risk of ICH $[6,7]$. Since the 1960s, the mortality of ICH has declined from 70 to $20 \%$ [4]. When our patient was admitted, we administered an infusion of $2400 \mathrm{U}$ (40 U/kg) of factor VIII. Rivera-Nunez et al. [3] suggested that a clotting factor should be provided as soon as possible and that the patient should be observed in the emergency department for at least $48 \mathrm{~h}$ after the operation. We immediately prepared for an operation. Fortunately, our hospital had sufficient factor VIII for infusion prior to the patient's operation. Sufficient factor VIII and a short preoperative period decreased postoperative complications and improved the patient's prognosis. The immediate treatment and operation were important for saving his life. Our patient's factor level was not measured because of limited time, but his family mentioned that it was $0.029 \mathrm{IU} / \mathrm{ml}$ at the beginning of 2014. The diagnosis of hemophilia in patients with ICH is sometimes neglected, especially in newborns. Treatment and prognosis vary between hemophilia A and factor XIII deficiency. Therefore, a differential diagnosis between hemophilia and factor XIII deficiency is needed. Hemophilia and factor XIII deficiency can both present with bleeding in patients with ICH. Factor XIII deficiency is always detected by a normal APTT and prothrombin time, and factors VIII, IX, and XI exhibit normal levels. Factor VIII is located on the X chromosome, and 
factor VIII deficiency can be inherited or acquired. Therefore, genotyping may be another way to distinguish hemophilia and factor XIII deficiency.

Perioperative management of hemophilia is one of the most important steps to save patients' lives, especially patients with a high-responding inhibitor, which is an antibody (primarily immunoglobulin G (IgG)). Approximately $25-30 \%$ of patients with severe hemophilia A have factor VIII inhibitors. We did not detect a factor VII inhibitor in our patient, and the effect of factor VIII was obvious. If a hemophilia patient has an inhibitor, we can use an Aminco Continuous Flow Celltrifuge; perform immunosuppression with.

Cyclophosphamide; and administer corticosteroids, $\varepsilon$-aminocaproic acid, and large doses of antihemophilic globulin (AHG) concentrates [8]. However, these treatments may lead to complications such as hemolysis and platelet dysfunction because of hyperfibrinogenemia, leukopenia, and Gram-negative sepsis. We infused our patient with $200 \mathrm{ml}$ fresh frozen plasma on the 1st postoperative day to increase blood capacity. However, plasma infusion alone may not decrease the danger of bleeding. Infusing only fresh frozen plasma may increase the risk of hemorrhagic infarction and acute SDH, which will require additional operation(s) [9]. We monitored the level of factor VIII activity 10 days after the operation, and it was $25.9 \%$. A total of $30 \%$ of plasma VIII factor is sufficient for preventing ICH in patients with hemophilia [10]. However, bleeding with a lower factor VIII activity level could still be controlled in our patient. Our patient was discharged after receiving infusions of factor VIII for 2 weeks, and the APTT was 34-57 s. Oculomotor paralysis remained when he was discharged from the hospital, and a follow-up clinic was needed. Titanium mesh reconstruction of a right bone flap was considered necessary after 3-6 months. Hemophilia in addition to a nervous system syndrome should be controlled by a follow-up clinic. Nutrient support was one of the most important factors in the postoperative recovery of our patient. Our patient was supported by a semi-liquid diet via a nasogastric tube during the first 2 postoperative days before he could eat by himself.

\section{Conclusion}

We treated our patient with a high-quality infusion of factor VIII, which helped save valuable time and improve his prognosis. Therefore, factor VIII infusion is the most important factor in treating SDH patients with a medical history of hemophilia A. We recommend monitoring coagulation function and determining the medical history once the patient is admitted, especially in the emergency department.

\footnotetext{
Abbreviations

AHG: Antihemophilic globulin; APTT: Activated partial thromboplastin time; CT: Computed tomography; ICH: Intracranial hemorrhage; SAH: Subarachnoid hemorrhage; SDH: Subdural hematoma
}

Acknowledgments

All acknowledgments are listed above, and there are no special declarations.

Availability of data and materials

The data and material are available. 
Ethics approval and consent to participate

This study was approved by the Ethics Committee of Peking Union Medical College Hospital.

\section{Consent for publication}

Written informed consent was obtained from the patient.

\section{Competing interests}

The authors declare that they have no competing interests.

Received: 14 April 2017 Accepted: 27 March 2018

Published online: 23 May 2018

\section{References}

1. Philipp C. The aging patient with hemophilia: complications, comorbidities, and management issues. Hematology Am Soc Hematol Educ Program. 2010;2010:191-6.

2. Santagostino E, Mancuso ME, Tripodi A, Chantarangkul V, Clerici M, Garagiola I, et al. Severe hemophilia with mild bleeding phenotype: molecular characterization and global coagulation profile. J Thromb Haemost. 2010;8:737-43.

3. Rivera-Núñez MA, Borobia AM, García-Erce JA, Martí de Gracia M, Pérez-Perilla P, Quintana-Díaz M. Acute complications and outcomes of acute head injury in adult patients with haemophilia. Eur J Emerg Med. 2014;21:380-3.

4. Ljung RC. Intracranial haemorrhage in haemophilia a and B. Br J Haematol. 2008;140:378-84.

5. Nelson MD Jr, Maeder MA, Usner D, Mitchell WG, Fenstermacher MJ, Wilson DA, et al. Prevalence and incidence of intracranial haemorrhage in a population of children with haemophilia. The hemophilia growth and development study. Haemophilia. 1999;5:306-12.

6. Witmer C, Presley R, Kulkarni R, Soucie JM, Manno CS, Raffini L. Associations between intracranial haemorrhage and prescribed prophylaxis in a large cohort of haemophilia patients in the United States. Br J Haematol. 2011; 152:211-6.

7. Nuss R, Soucie JM, Evatt B. Hemophilia surveillance system project investigators. Changes in the occurrence of and risk factors for hemophilia-associated intracranial hemorrhage. Am J Hematol. 2001;68:37-42.

8. Edson JR, McArthur JR, Branda RF, McCullough JJ, Chou SN. Successful management of a subdural hematoma in a hemophiliac with an anti-factor VIII antibody. Blood. 1973;41:113-22.

9. Meguro T, Higashi H, Nishimoto K, Nakamura T. A surgical case of subdural hematoma with hemophilia a. No Shinkei Geka. 2004;32:1039-43.

10. Toyama M, Ishikawa H, Ishii R, Okada K. Acute and subacute intracranial hepatoma with hemophilia A-two cases report. No Shinkei Geka. 1978;6:275-9.

\section{Submit your next manuscript to BioMed Central and we will help you at every step:}

- We accept pre-submission inquiries

- Our selector tool helps you to find the most relevant journal

- We provide round the clock customer support

- Convenient online submission

- Thorough peer review

- Inclusion in PubMed and all major indexing services

- Maximum visibility for your research

Submit your manuscript at www.biomedcentral.com/submit 